\title{
Estudo linguístico-etnográfico em comunidade paranaense de imigrantes ucranianos: do passado ao presente
}

Neiva Mara Zanin GARCIA *

Resumo: Este artigo tem como objetivo abordar os procedimentos teórico-metodológicos, bem como os resultados desta pesquisa referentes à descrição do atual estágio da língua falada entre os habitantes descendentes de imigrantes ucranianos em um distrito paranaense, localizado ao sul do Estado. Este estudo foi norteado pelos princípios teóricos da sociolinguística, particularmente os que se referem a fenômenos decorrentes do contato linguístico, considerando-se, no caso, o contato entre falantes do português local e a variante ucraína trazida pelos primeiros povoadores eslavos, no final do século XIX. Para tal, investigamos a mudança linguística em tempo real e tempo aparente.

Palavras-chave: Línguas em contato; Mudança linguística em tempo aparente e tempo real; Aculturação social.

Abstract: This article deals the theoretical-methodological
procedures and the results of this research, about the current stage
of the spoken language by the Ukrainians immigrants descendants
who lives in a paranaense community located at the south of the
State. The theoretical discussion is based on the principles of the
Sociolinguistic, particularly the referents to the phenomena of
linguistics contact between the Portuguese language spoken by
the inhabitant in this community and the Ukrainian variant of the

* Mestrado em Estudos da Linguagem pela Universidade Estadual de Londrina, em 2008. Contato: ngarciazanin@yahoo.com.br. 
first Slavic settlement brought in the end of the nineteen century. For this, we followed the apparent and the real time research method.

Keywords: Languages in contact; Linguistic change in apparent time and real time; Social acculturation.

\section{Introdução}

Decorridos mais de cem anos da chegada dos primeiros imigrantes ao Brasil e face à grande diversidade linguística e cultural apresentada pela sua interação com o meio que os acolheu, faz-se necessário estudar o estágio atual dessas línguas minoritárias em contato com o português falado no Brasil. Desta forma, optamos por pesquisar a fala de moradores da comunidade de Dorizon, distrito paranaense colonizado por imigrantes ucranianos, que ainda mantém uma população formada, em sua maioria, por descendentes desse grupo.

Outro fator relevante para a escolha dessa comunidade como local de pesquisa, e como objeto de estudo os falares locais, diz respeito à pesquisa realizada por Miguel Wouk na década de 1960 em Dorizon. Esta obra, publicada em 1981, permitiu o desenvolvimento de um estudo das mudanças linguísticas ocorridas neste intervalo de quarenta anos.

Sabendo-se que a cultura exprime a heranca social de um grupo humano, visto que a sua transmissão se faz pelo convívio das novas gerações com as mais antigas (SILVA NETO, 1957), uma vez testada a mudança com base em dados dos tempos real e aparente, procedemos a um encaixamento histórico em tempo real (TARALLO, 1985). Isto foi possível por meio da comparação dos dados obtidos neste trabalho com os da primeira investigação, devido à distância de quarenta anos entre uma e outra pesquisa. Buscamos, na sequência, verificar as mudanças linguísticas em curso, portanto, no nível sincrônico, com base em variáveis sociais de natureza diastrática, diageracional e diassexual, bem como analisar o processo de aculturação nos campos social, religioso e 
cultural, contribuindo, assim, com a descrição do português falado no Brasil.

Wouk (1981) traz em seu estudo uma relação de fatos fonéticos do português brasileiro que dificultavam aos imigrantes e seus descendentes a perfeita reprodução dos sons. Desta forma, elegemos, dentre outros, analisar o ditongo nasal ão, fato fonético que apresentou variações mais salientes na fala dos informantes selecionados.

\section{Línguas em contato}

O contato entre povos de línguas e culturas diferentes é observado desde o início da humanidade. A noção de variação linguística já era utilizada por gregos e romanos. Assim, a herança linguística desses povos deu origem aos dialetos empregados nas línguas literárias do século XII. Não há uma definição precisa para "dialeto". Um dialeto pode ser toda uma língua por ser derivada de uma protolíngua, ou de uma maneira ou estilo de fala alta ou baixa, ou, ainda, de cada maneira de falar de uma pessoa ou de um lugar (THUN, 2005).

Podemos dizer que duas línguas estão em contato quando são usadas pelos mesmos indivíduos, ou seja, quando existe uma situação de bilinguismo (ou multilinguismo) em que falantes bilíngues (ou multilíngues) constituem o locus do contato. Esta situação sociolinguística é uma das mais favoráveis às mudanças linguísticas, em que ocorrem fenômenos de empréstimos ou transferências na estrutura de ambas as línguas (SILVACORVALÁN, 1989, p. 178).

Segundo Heye e Vandresen (2006, p. 393), nos trabalhos sobre línguas em contato no Brasil discutem-se os conceitos de bilinguismo, diglossia e mudança de código, face às diferentes situações encontradas ao longo da convivência do português com as línguas minoritárias. A coexistência de duas línguas em diferentes espaços sociais deve ser analisada segundo a condição particular dos indivíduos que se tornaram bilíngues. Esta condição é caracterizada pelo contexto e pela idade de aquisição, pela variação 
de uso das línguas (função tópica) e, ainda, pela manutenção ou pelo abandono de uma ou outra língua em decorrência de fatores sociais e comportamentais.

A condição de bilíngue se modifica na trajetória de vida dos indivíduos e assume diferentes contornos (estágios) em relação ao domínio e à variação de uso em ambas as línguas. Estes estágios são estabelecidos pelas funções de uso das línguas em contextos e situações diferentes (familiar, social, escolar, profissional, etc.). Desta forma, a condição particular de indivíduos bilíngues é dinâmica, ou seja, eles podem tornar-se proficientes em ambas as línguas ou partir em direção ao monolinguismo, abandonando, assim, o uso em uma das línguas.

Neste contexto, destaca-se a necessidade de refletir sobre bilinguismo e bilingualidade, pois, enquanto o bilingüismo corresponde à coexistência de duas línguas como meio de comunicação em um determinado espaço social, ou seja, um estado situacionalmente compartimentalizado de uso de duas línguas, a bilingualidade se volta para estágios distintos de bilinguismo, pelos quais os indivíduos portadores de condição bilíngue passam na sua trajetória de vida (HEYE, 2003, p. 233).

\subsection{Bilinguismo individual}

Moreno Fernández (1998, p. 213) discute o conceito de Weinreich (1953) no que diz respeito à relação entre o sistema linguístico do bilíngue quanto à representação mental das línguas, distinguindo três tipos de bilinguismo:

a) Bilinguismo coordenado: os significados das palavras equivalentes nas duas línguas remetem a conceitos diferentes ou parcialmente diferentes;

b) Bilinguismo composto: o significado das palavras equivalentes remete ao mesmo conceito ou referente ou a conceitos totalmente equivalentes;

c) Bilinguismo subordinado: consiste na existência de uma língua dominante e uma dominada; as palavras da língua dominada são interpretadas a partir das palavras equivalentes da língua dominante. 


\subsection{Bilinguismo social}

O bilinguismo é um fenômeno que pode causar efeitos não só nos indivíduos, mas também nas sociedades. Uma comunidade bilíngue pode ser definida como aquela em que se falam duas línguas ou em que seus componentes, ou parte deles, são bilíngues. A este fenômeno subjazem fatores de ordem e social: i) povos se expandem em territórios cuja língua não é a mesma de seu lugar de origem; ii) ocorrem processos de unificação política para a criação de grandes Estados, em que o grupo do poder sobrepõe seus hábitos linguísticos e sociais; iii) países ou cidades que recebem grandes contingentes de imigrantes; iv) lugares de contatos internacionais, em geral comerciais, econômicos, políticos e turísticos, ou seja, cosmopolitismo (SIGUÁN; MACKEY, 1986 apud MORENO FERNÁNDEZ, 1998, p. 216-217).

Em suma, o bilinguismo ocasiona uma divisão quanto a uso e funções sociais entre as línguas em contato em uma determinada comunidade linguística, fenômeno este que remete a uma distinção entre bilinguismo e diglossia, esta última entendida como uma desigualdade funcional das línguas, decorrente de fatores culturais (grupo de poder - grupo dominado); lingüísticos (distância entre as línguas, inteligibilidade, difusão, número de falantes no mundo); e fatores afetivos.

\section{Diglossia}

De acordo com Silva-Corvalán (1989), o conceito de diglossia caracteriza situações de bilinguismo em que cada língua tem uma função específica, uma língua de domínio do poder público, de maior prestígio, denominada variedade alta e uma variedade baixa, sobreposta à língua alta. Alguns autores têm estendido o termo diglossia para referir-se ao uso diglóssico de línguas complementares diferentes. Como exemplo, o espanhol e o guarani, no Paraguai, onde quase toda a população é bilíngue. Ambas são línguas oficiais. O espanhol, porém, é considerado a variedade alta e o guarani, a variedade baixa, de acordo com o uso especializado em diferentes domínios. 
Heye (2006, p. 76) reconhece que tanto o bilinguismo quanto a diglossia são variáveis contínuas, tratadas como variáveis dicotômicas. Nesse sentido, uma situação de bilinguismo sem diglossia é vista como transicional, podendo conduzir a uma situação de ausência de bilinguismo e de diglossia.

\section{Procedimentos teórico-metodológicos}

\subsection{Mudança linguística em tempo aparente e tempo real}

Segundo Tarallo (1985, p. 64-65), a estrutura de uma língua só será totalmente entendida desde que se compreendam efetivamente os processos históricos de sua configuração. As forças que atuam no momento sincrônico presente são (ou deveriam ser) as mesmas que atuaram no passado, e vice-versa. Portanto, uma teoria da mudança linguística deve guiar-se por uma articulação teórica e metodológica entre presente-passado e presente. Este processo consiste, na prática, em iniciar a investigação no momento presente, voltar-se ao passado para o devido encaixamento histórico das variantes, retornando-se, a seguir, ao presente para o fechamento do ciclo da análise. Quanto à realização da análise em tempo aparente, uma vez feita a análise dos fatores linguísticos condicionadores internos, devem as variantes ser correlacionadas ao fator idade, por meio de um recorte transversal da amostra sincrônica em função da faixa etária dos informantes.

Para a presente pesquisa foi adotada tal posição metodológica, que compreende a análise das variações e mudanças linguísticas em tempo real e tempo aparente. Para que este processo fosse viabilizado contamos com o estudo já realizado por Wouk na década de 1960 na mesma comunidade ora estudada, tornando possível, assim, o cotejo entre os dados da primeira investigação e os da pesquisa que ora realizamos.

Desta forma, optamos por selecionar o mesmo contexto linguístico, seguindo os princípios teórico-metodológicos da dialetologia e da sociolinguística no que tange às questões de línguas em contato e suas vertentes. 
Tal posicionamento é embasado nos postulados de Labov (1996, p. 141), no que diz respeito ao Estudo de Tendência:

El tipo más simple de réplica es un estudio de tendencia. Enumeramos la población general del mismo modo, extraemos la población de la muestra del mismo modo, obtenemos los datos y los analizamos del mismo modo pero un número $x$ de años después -. Si estamos tratando con una población urbana grande, es muy improbable que la nueva muestra incluya a ninguno de los mismos individuos. Pero si seguimos los mismos procedimientos controlados, la muestra será representativa, y producirá el tipo de réplica más confiable.

Para que tal estudio produzca un retrato significativo de la evolución lingüística, es esencial que la comunidad haya permanecido en un estado más o menos estable durante el período intermedio. ${ }^{1}$

Os dados da nova pesquisa indicam que a comunidade de Dorizon não sofreu mudanças drásticas nos 40 anos decorridos. Este distrito ainda é governado sob a jurisdição do município de Mallet (tal como era na década de 1960), a densidade demográfica é estável (1.934 habitantes), constituída predominantemente por descendentes de imigrantes ucranianos, ou seja, não houve incursão

\footnotetext{
${ }^{1} \mathrm{O}$ tipo mais simples de réplica é o estudo de tendência. Selecionamos a população geral do mesmo modo, extraímos a amostra da população do mesmo modo - porém um número $\mathrm{x}$ de anos depois -. Se estamos tratando com uma população urbana grande, é muito improvável que a nova amostra inclua alguns dos mesmos indivíduos. Mas se seguirmos os mesmos procedimentos controlados, a amostra será representativa, e produzirá um tipo de réplica mais confiável. Para que tal estudo produza um retrato significativo da evolução linguística, é essencial que a comunidade tenha permanecido em um estado mais ou menos estável durante o período intermediário. [Tradução nossa]
} 
de novos habitantes e a agricultura ainda é a atividade principal de seus moradores. Desta forma, acreditamos que são pertinentes para este estudo os moldes metodológicos da análise em tempo aparente e tempo real, de acordo com o conceito de estudo de tendência proposto por Labov (1996).

Como não foi possível localizar os mesmos informantes entrevistados por Wouk, seguimos os critérios de seleção de informantes citados por ele no manual de investigação linguística, capítulo que faz parte de seu livro (WOUK, 1981, p. 133): ser pessoa do lugar; ser filho de gente do lugar; conhecer bem as formas de cultura da comunidade; se casado, deve a esposa ser também do lugar; não ter viajado; não ter feito o serviço militar; e não ter trabalhado fora por muito tempo. Assim, foi possível traçarmos o perfil do informante adequado à nova pesquisa.

Com a evolução dos estudos dialetológicos e o reconhecimento da relevância dos fatores extralinguísticos na análise e explicação das variações, faz-se necessária a abordagem da pluridimensionalidade estrutural de uma dada comunidade ou grupo de falantes. O número de dimensões a ser observado é ilimitado, dependendo da estrutura da sociedade. De acordo com Thun (2005), as seguintes dimensões estruturais são as mais relevantes:

- Dialingual: comparação de uma mesma língua falada por pessoas de origens diferentes;

- Diatópica: pesquisa com número indeterminado de lugares;

- Diatópico-cinético: movimento combinado no espaço (topostático e topodinâmico);

- Diastrática: dimensão entre classes sociais;

- Diageracional: faixas etárias;

- Diassexual: homens/mulheres;

- Diafásica: estilos da fala, de acordo com o tema, as circunstâncias e a formação cultural;

- Diarreferencial: é um estudo seletivo, porém não contrastivo, com parâmetros na fala objetiva (emprego da língua para falar sobre as coisas), e na fala metalinguística (uso da língua para falar sobre a língua). 
$\mathrm{Na}$ perspectiva para novos estudos, a dialetologia pluridimensional consiste em combinar a dialetologia areal com a sociolinguística e analisar as redes de comunicação entrelaçadas entre elas, ou seja, as relações diagonais. Em uma visão pragmática, a dialetologia analisa a superfície, ao passo que a sociolinguística analisa a profundidade, mas não em dimensão diatópica. Assim, a junção da dialetologia com a sociolinguística viabiliza a análise diagonal da variação linguística. Como exemplo, um falar rural pode estar presente na camada periférica de uma cidade.

Assim, procedemos ao levantamento dos dados em tempo aparente, por meio de variáveis sociais diastráticas, diageracionais e diassexuais, para que fosse possível realizar uma comparação com os dados da primeira investigação realizada por Wouk, a fim de comprovar as mudanças linguísticas ocorridas nesse intervalo de 40 anos.

\subsection{As variáveis não linguisticas}

Às variações linguísticas estão intrínsecos agentes internos e externos, ou seja, além dos fatores estruturais, as mudanças em uma língua podem ser atribuídas a fatores de ordem não linguística. Estudos recentes apontam as variáveis sociais, sexo/gênero, idade, escolaridade e classe social, dentre outras, como fenômenos determinantes quanto ao uso da língua falada e escrita. No entanto, variáveis linguísticas ou não linguísticas não ocorrem separadamente, "mas operam num conjunto complexo de correlações que inibem ou favorecem o emprego de formas variantes semanticamente equivalentes" (MOLLICA, 2004, p. 27).

\subsubsection{A variável gênero/sexo}

Em algumas sociedades há diferenças marcantes entre a fala de homens e mulheres. No entanto, estudos revelam que, em alguns casos, os fatores que determinam uma mudança linguística não estão relacionados ao sexo do falante, mas sim à atitude tomada em relação à linguagem e, a esta questão, estão implícitos fatores 
de ordem social e de contexto de fala. Nesse sentido, argumenta Labov (1969, p. 29-30):

In some societies, there are striking differences between men's and women's speech, but in the United States, we do not find wide-spread variation in the actual features of language used by the sexes. There are marginal examples: men are more apt to say 'Fill' er up' than women are; men use more obscene language than women do in public. But the major differences between the sexes are in the important areas of attitudes towards language. The sociolinguistic behavior of women is quite different from that of men because they respond to the commonly held normative values in a different way ... In general, women are more sensitive to overt social correction, and use more prestige forms than men. But this difference is not independent of social class. ${ }^{2}$

Assim, aos efeitos da variável gênero/sexo estão implícitos fatores mais complexos, que devem ser examinados em relação a outras variáveis, como classe social, idade, estilo de fala.

\footnotetext{
${ }^{2}$ Em algumas sociedades, há diferenças marcantes na fala de homens e mulheres, mas nos Estados Unidos, nós não encontramos uma variação muito grande nas características da linguagem determinadas pelo sexo. Existem exemplos marginais: homens estão mais aptos a dizer 'você está me enchendo' do que mulheres; homens usam mais linguagem(ns) obscena(s) em público do que as mulheres. Mas, a maior diferença entre os sexos está nas importantes áreas das atitudes tomadas em relação à linguagem. O comportamento sociolinguístico das mulheres é um tanto diferente do dos homens porque ambos respondem aos valores normativos mais comuns de diferentes maneiras... No geral, as mulheres são mais sensíveis para manifestar as correções sociais, e usam mais as formas de prestígio do que os homens. Mas estas diferenças não são independentes da classe social. [Tradução nossa]
} 


\subsubsection{Relevância da variável escolaridade}

De acordo com Votre (2004, p. 51), a escola pode atuar como geradora de mudanças na fala e na escrita das pessoas que as frequentam, preservando as formas de prestígio, isto é, contribuindo para a resistência de certas mudanças linguísticas em relação à mobilidade da língua considerada em seu uso. Nesse sentido, faz-se necessária uma análise mais detalhada dos efeitos gerados pela variável escolaridade em correlação à variação, continuidade e mudança linguística.

No Brasil, ainda não se conferiu a devida atenção à influência da diversidade linguística no processo educacional. A implementação da política pedagógica recomendada pelos linguistas deve levar em conta as variações correntes no português falado em nosso país. Nessa questão é imprescindível que se leve em conta a situação sociolinguística brasileira (BORTONI-RICARDO, 2005).

\subsubsection{Idade e mudança linguística}

Estudos demonstram não haver ainda evidências empíricas que comprovem até que ponto a língua falada pelo indivíduo pode realmente mudar no decorrer dos anos. De acordo com Naro (2004, p. 44), a posição "clássica", aceita por linguistas gerativistas e sociolinguistas, postula haver uma estabilização no processo de aquisição da linguagem no início da puberdade. Desta forma, o acesso aos dispositivos cognitivos, que possibilitam a sua manipulação (a chamada faculdade da linguagem), fica bloqueado nesta fase da vida, impossibilitando mudanças significativas na gramática do indivíduo e apenas mudanças esporádicas podem ocorrer. Assim, a fala de uma pessoa de 60 anos hoje, representa a língua de quarenta e cinco anos atrás.

Labov (1976, p. 70) cita a pesquisa de Gauchat (1905), na Súça, como um estudo em tempo aparente sobre a mudança fonética no seio de uma comunidade. Gauchat observou e registrou as divergências em/de seis traços/aspectos fonológicos na fala de 
três gerações: falantes com mais de 60 anos, entre 30 e 60 anos, e com menos de 30 anos. Em 1929, uma geração mais tarde, Herman voltou à Suíça a fim de pesquisar quatro desses aspectos (LABOV, 1976). Seus resultados confirmaram que as descobertas de Gauchat indicavam bem uma mudança histórica na fala dos moradores dessa comunidade, pois três dos quatro aspectos foram considerados progressivos dentro de um mesmo período de tempo. No entanto, Herman verificou que os falantes iam adotando a variante apropriada conforme a sua idade, contrariando, neste caso, a hipótese clássica de estabilidade linguística a partir da fase de puberdade. Ao mesmo tempo, Herman mostrou que a dimensão do tempo real é essencial para dar uma vista exata no panorama linguístico de uma dada comunidade.

\subsection{Instrumento de coleta de dados}

Quanto ao instrumento de coleta de dados, adequamos o Questionário Fonético-Fonológico do Atlas Lingüistico do Brasil (ALiB), versão 2001 (COMITÊ, 2001), aos objetivos desta pesquisa. Assim, foram introduzidos os itens investigados por Wouk que não constavam daquele instrumento de coleta.

Questionário Fonético-Fonológico (QFF): contém 66 questões, das quais 61 são coincidentes com o ALiB e 5 são questões incluídas: questão 10 (FEIJÃO), questão 11 (BUZINAR), questão 17 (PINHÃO), questão 18 (CHOCOLATE) e questão 19 (FACÃO).

Para a análise do ditongo nasal ão selecionamos 9 questões (QFF) que contêm como resposta vocábulos formados por esse ditongo: questão 2 (TELEVISÃO), questão 10 (FEIJÃO), questão 17 (PINHÃO), questão 19 (FACÃO), questão 32 (CALÇÃO), questão 33 (UNIÃO), questão 36 (PROCISSÃO), questão 38 (PERDÃO) e questão 45 (CORAÇÃO). 


\subsection{Perfil e escolha dos informantes}

Quanto à variável faixa etária, estabelecemos três grupos: grupo 1 (20-40 anos), grupo 2 (50-65 anos) e grupo 3 (mais de 70 anos). Quanto à variável gênero/sexo, foram entrevistados informantes masculinos e femininos. A propósito da variável escolaridade, foram fixados três níveis: fundamental, ensino médio e ensino superior. Quanto ao grupo de informantes de faixa etária 1 , não foi possível localizar a informante do sexo feminino com nível escolar fundamental, enquanto que no nível de escolaridade superior, não foi possível encontrar informantes masculinos de nenhum grupo de faixa etária.

Os quadros apresentados a seguir demonstram como ficou delineado o perfil dos informantes de acordo com as variáveis sociais estabelecidas.

\begin{tabular}{|l|c|c|c|}
\hline FAIXA ETÁRIA & MASCULINO & FEMININO & TOTAL (\%) \\
\hline $18-40$ & 3 & 3 & $6(46,2)$ \\
\hline $50-65$ & 2 & 2 & $4(30,8)$ \\
\hline+70 & 2 & 1 & $3(23,0)$ \\
\hline TOTAL & 7 & 6 & $13(100,0)$ \\
\hline
\end{tabular}

Quadro 1 - Perfil dos informantes por faixa etária e gênero/ sexo

\begin{tabular}{|c|c|c|c|}
\hline $\begin{array}{c}\text { GRAU DE } \\
\text { ESCOLARIDADE }\end{array}$ & MASCULINO & FEMININO & TOTAL (\%) \\
\hline Fundamental & 5 & 2 & $7(53,8)$ \\
\hline Ensino Médio & 2 & 2 & $4(30,8)$ \\
\hline Superior & - & 2 & $2(15,4)$ \\
\hline TOTAL & 7 & 6 & $13(100,0)$ \\
\hline
\end{tabular}

Quadro 2- Perfil dos informantes por grau de escolaridade e gênero/sexo 


\begin{tabular}{|l|c|c|c|c||}
\hline $\begin{array}{c}\text { FAIXA } \\
\text { ETÁRIA }\end{array}$ & FUNDAMENTAL & $\begin{array}{c}\text { ENSINO } \\
\text { MÉDIO }\end{array}$ & SUPERIOR & $\begin{array}{c}\text { TOTAL } \\
\mathbf{( \% )}\end{array}$ \\
\hline $18-40$ & 2 & 2 & 2 & $6(46,2)$ \\
\hline $50-65$ & 3 & 1 & - & $4(30,8)$ \\
\hline+70 & 2 & 1 & - & $3(23,0)$ \\
\hline TOTAL & 7 & 4 & 2 & $13(100,0)$ \\
\hline
\end{tabular}

Quadro 3 - Perfil dos informantes por faixa etária e grau de escolaridade

\subsection{Entrevistador}

A dialetologia é um trabalho de campo, ou seja, "um saber de experiências feito". A recolha dos dados linguísticos é feita concomitantemente com a colheita da cultura material (SILVA NETO, 1957, p. 35). Assim, optamos por realizar todos os inquéritos pessoalmente, com o intuito de, além dos dados linguísticos, observarmos efetivamente o contexto sociocultural de cada informante e, assim, obter dados reveladores do processo de sua aculturação.

\subsection{Dados técnicos da gravação}

Para a gravação das entrevistas utilizamos um gravador portátil SONY (rádio-gravador) WM-F36 com microfone e fone de ouvidos, de corrente a pilha, e fitas cassete da marca TDK, de 90'. As gravações foram reproduzidas em $\mathrm{CD}$, para audição e transcrição, na Sala de Projetos 169, no Centro de Letras e Ciências Humanas da UEL, com eliminador de ruídos.

\subsection{Transcrição grafemática e fonética}

A transcrição grafemática foi efetuada de acordo com as resoluções tomadas no V WorkALiB, em 2005 (COMITÊ, 2005). As entrevistas foram transcritas integralmente, constituindo um 
continuum de informações interligadas, perfazendo um total de aproximadamente 600 páginas. Quanto ao tempo de gravação, as entrevistas oscilaram entre 60 e 80 minutos cada. $\mathrm{Na}$ transcrição fonética utilizamos basicamente o Alfabeto Fonético Internacional (IPA) com algumas adaptações. Foram transcritos foneticamente os segmentos que, a priori, foram selecionados para receber tratamento fonético.

\subsection{Localidade}

As características da localidade escolhida enquadram-se perfeitamente nas condições sugeridas por Silva Neto (1957): ser comunidade: (i) antiga, onde o tipo de vida é tradicional e conservador; (ii) de mais ou menos 2.000 habitantes; (iii) isolada de grandes centros; (iv) em que a vida não seja industrial (atividade moderna), mas pastoril ou agrária.

\section{Descrição e análise dos dados}

Nesta pesquisa, detectamos quatro variantes de ão:

1. $\tilde{\mathbf{o}} \tilde{\mathbf{w}}=$ vogal posterior média fechada nasal e a semivogal velar nasal;

2. $\tilde{\mathbf{\jmath}} \tilde{\mathbf{w}}=$ vogal posterior média aberta nasal e a semivogal velar nasal;

3. $\tilde{\mathbf{a}} \tilde{\mathbf{w}}=$ vogal central baixa aberta nasal e a semivogal velar nasal;

4. $\tilde{\mathbf{a}} \tilde{\mathbf{w}}=$ vogal posterior baixa nasal e a semivogal velar nasal. 
4.1 Registros das variantes do ditongo nasal ão conforme a variável faixa etária

\begin{tabular}{|c|c|c|}
\hline Variável & Quantidade & Porcentagem \\
\hline$\tilde{\mathbf{o}} \tilde{\mathbf{w}}$ & 10 & $17,7 \%$ \\
\hline$\tilde{\mathbf{0}} \tilde{\mathbf{w}}$ & 10 & $17,7 \%$ \\
\hline$\tilde{\mathbf{a}} \tilde{\mathbf{w}}$ & 13 & $23,1 \%$ \\
\hline$\tilde{\mathbf{a}} \tilde{\mathbf{w}}$ & 23 & $41,5 \%$ \\
\hline Total & 56 & $100 \%$ \\
\hline
\end{tabular}

Quadro 4 - Variáveis do ditongo nasal ão - registros da faixa etária 3

De acordo com os dados, os três informantes da faixa etária 3 (+ de 70 anos) apresentam índices equilibrados de produção nas

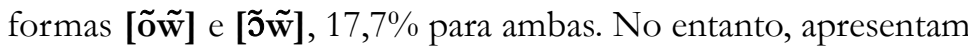
um percentual maior para a forma $\tilde{\mathbf{a}} \tilde{\mathbf{w}}(5,4 \%)$, em relação a cada

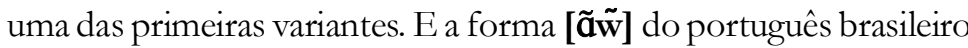
lidera com um índice de $41,5 \%$ dos registros apresentados para o ditongo nasal ão. Tal fato demonstra que, embora estes informantes

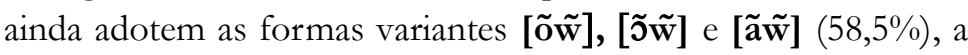
forma $[\tilde{\mathbf{a}} \tilde{\mathbf{w}}]$ prevista pelo português brasileiro já se encontra incorporada em sua fala, não se confirmando, assim, na nova pesquisa, os postulados de Wouk (1981), no que diz respeito à "aversão" ao som português ão. 


\begin{tabular}{|c|c|c|}
\hline Variável & Quantidade & Porcentagem \\
\hline$\tilde{\mathbf{o}} \tilde{\mathbf{w}}$ & 7 & $8,4 \%$ \\
\hline$\tilde{\mathbf{0}} \tilde{\mathbf{w}}$ & 3 & $3,6 \%$ \\
\hline$\tilde{\mathbf{a}} \tilde{\mathbf{w}}$ & 19 & $22,9 \%$ \\
\hline$\tilde{\mathbf{a}} \tilde{\mathbf{w}}$ & 54 & $65,1 \%$ \\
\hline Total & 83 & $100 \%$ \\
\hline
\end{tabular}

Quadro 5 - Variáveis do ditongo nasal ão - registros da faixa etária 2

Quanto aos informantes da faixa etária 2 (50-65 anos), observamos uma queda significativa nos índices de produção das

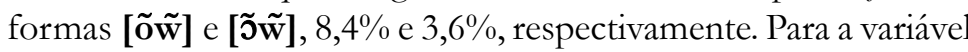
[ã̃ ], o índice $22,9 \%$ mantém-se equilibrado em relação ao índice apresentado pelos informantes da faixa etária $3(23,1 \%)$. Quanto à

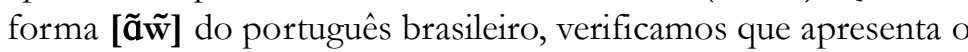
maior índice de registros, $65,1 \%$. Tal fato demonstra que há uma tendência, nas gerações mais novas, a adotar a forma do português brasileiro, embora ainda apresentem registros em todas as outras formas variantes. Este fato é atribuído à situação de aquisição de cada uma das línguas, pois são informantes descendentes de segunda geração, ou seja, pais brasileiros e avós imigrantes. Esta situação é caracterizada pela coexistência do contato linguístico ucraniano-português no contexto familiar desde os primeiros anos de vida; portanto, a aquisição das duas línguas se deu ao mesmo tempo, com reforço da língua portuguesa no contexto escolar. 


\begin{tabular}{|c|c|c|}
\hline Variável & Quantidade & Porcentagem \\
\hline$\tilde{\mathbf{o}} \tilde{\mathbf{w}}$ & 0 & $0 \%$ \\
\hline$\tilde{\mathbf{0}} \tilde{\mathbf{w}}$ & 0 & $0 \%$ \\
\hline$\tilde{\mathbf{a}} \tilde{\mathbf{w}}$ & 32 & $23 \%$ \\
\hline$\tilde{\mathbf{a}} \tilde{\mathbf{w}}$ & 107 & $77 \%$ \\
\hline Total & 139 & $100 \%$ \\
\hline
\end{tabular}

Quadro 6 - Variantes do ditongo nasal ão - registros da faixa etária 1

Quanto aos informantes da faixa etária 1 (18-40 anos), os

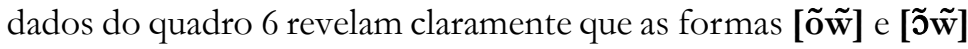
apresentam-se totalmente ausentes da fala deste grupo de informantes. Supomos ser a forma [ãâw] uma fase intermediária. Apresenta um índice de $23 \%$ de produção e está equilibrado em relação aos registros dos grupos de faixas etárias 2 e $3(22,9 \%$ e

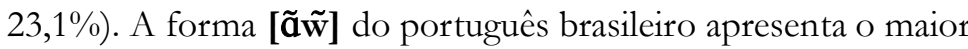
índice de produção, $77 \%$.

A significativa mudança observada neste grupo de informantes descendentes de terceira geração indica que os jovens incorporam com maior rapidez a forma prevista pela norma culta do português brasileiro. Esta situação é decorrente do aprendizado no contexto familiar, no qual os pais já se encontravam totalmente integrados ao meio brasileiro, reforçado pelo ingresso no contexto escolar e pelo convívio social. Para este grupo de faixa etária, observamos que não se estabelece uma situação de bilinguismo. 
4.2 Registros das variantes do ditongo nasal ão conforme a variável gênero/ sexo

\begin{tabular}{|c|c|c|}
\hline $\begin{array}{c}\text { Gênero / } \\
\text { Sexo }\end{array}$ & Quantidade & Porcentagem \\
\hline Homens & 10 & $58,8 \%$ \\
\hline Mulheres & 7 & $41,2 \%$ \\
\hline Total & 17 & $100 \%$ \\
\hline
\end{tabular}

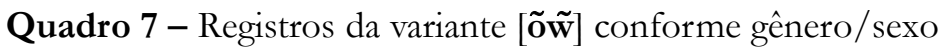
do informante

Ao compararmos os dados, constatamos que a primeira forma de aquisição desse som nasal abordada por Wouk (1981) ainda se faz presente na fala dos informantes entrevistados. No entanto, os homens estão preservando mais esta forma variante do ditongo nasal ão (ao), com um percentual de 17,6\% de registros a mais que as mulheres.

\begin{tabular}{|c|c|c|}
\hline $\begin{array}{c}\text { Gênero / } \\
\text { Sexo }\end{array}$ & Quantidade & Porcentagem \\
\hline Homens & 8 & $61,7 \%$ \\
\hline Mulheres & 5 & $39,3 \%$ \\
\hline Total & 13 & $100 \%$ \\
\hline
\end{tabular}

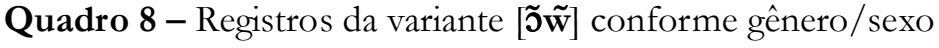
do informante 
Os dados revelam que, para esta variante do ditongo nasal ão, os homens também apresentam maiores índices de registro em relação às mulheres, ou seja, um percentual de $22,4 \%$ a mais. Tal fato indica que, embora esta variável ainda se apresente na fala das mulheres, elas demonstram menor incidência de uso em relação aos homens. Neste caso, confirmam-se os postulados de Labov (1969), quando afirma que, em algumas comunidades de fala, as mulheres se revelam linguisticamente mais orientadas para as variantes de prestígio, devido aos papéis sociais tradicionalmente imbuídos de maior formalismo, como contatos com escola, médicos, enfermeiros.

\begin{tabular}{|c|c|c|}
\hline $\begin{array}{c}\text { Gênero / } \\
\text { Sexo }\end{array}$ & Quantidade & Porcentagem \\
\hline Homens & 47 & $73,4 \%$ \\
\hline Mulheres & 17 & $26,6 \%$ \\
\hline Total & 64 & $100 \%$ \\
\hline
\end{tabular}

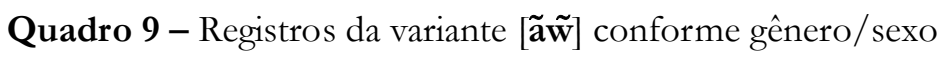
do informante

Ao compararmos os dados, podemos notar o maior rendimento desta variante entre os homens, com um percentual de $46,8 \%$ a mais. As mulheres, por outro lado, demonstram uma diminuição gradativa quanto ao uso das formas variantes não previstas pela norma do português brasileiro referentes ao ditongo

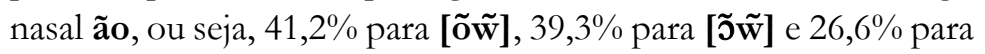

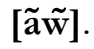




\begin{tabular}{|c|c|c|}
\hline $\begin{array}{c}\text { Gênero / } \\
\text { Sexo }\end{array}$ & Quantidade & Porcentagem \\
\hline Homens & 91 & $49,4 \%$ \\
\hline Mulheres & 93 & $50,6 \%$ \\
\hline Total & 184 & $100 \%$ \\
\hline
\end{tabular}

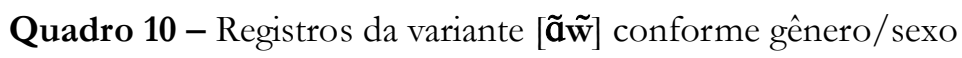
do informante

Para a forma [ [ãw] do português brasileiro, os homens e as mulheres apresentam índices muito equilibrados de produção, $49,4 \%$ e $50,6 \%$, respectivamente. Tal fato indica que, embora os homens tenham apresentado maior tendência de uso em relação às mulheres nas outras três formas variantes do ditongo nasal ão, chegam com um índice praticamente igual quanto aos registros da

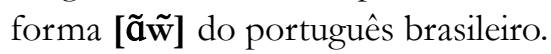

\subsection{Registros das variantes do ditongo nasal ão conforme a variável escolaridade}

\begin{tabular}{|c|c|c|}
\hline Nível Escolar & Quantidade & Porcentagem \\
\hline Fundamental & 15 & $88,3 \%$ \\
\hline Médio & 2 & $11,7 \%$ \\
\hline Superior & 0 & $0 \%$ \\
\hline Total & 17 & $100 \%$ \\
\hline
\end{tabular}

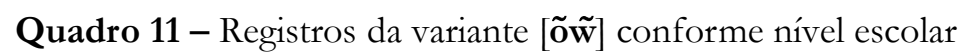
do informante 


\begin{tabular}{|c|c|c|}
\hline Nível Escolar & Quantidade & Porcentagem \\
\hline Fundamental & 11 & $84,6 \%$ \\
\hline Médio & 2 & $15,4 \%$ \\
\hline Superior & 0 & $0 \%$ \\
\hline Total & 13 & $100 \%$ \\
\hline
\end{tabular}

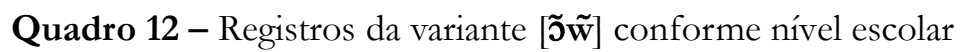
do informante

\begin{tabular}{|c|c|c|}
\hline Nível Escolar & Quantidade & Porcentagem \\
\hline Fundamental & 27 & $42,2 \%$ \\
\hline Médio & 29 & $45,3 \%$ \\
\hline Superior & 8 & $12,5 \%$ \\
\hline Total & 64 & $100 \%$ \\
\hline
\end{tabular}

Quadro 13 - Registros da variante [ã $\tilde{\mathbf{w}}]$ conforme nível escolar do informante

\begin{tabular}{|c|c|c|}
\hline Nível Escolar & Quantidade & Porcentagem \\
\hline Fundamental & 89 & $48,4 \%$ \\
\hline Médio & 61 & $33,1 \%$ \\
\hline Superior & 34 & $18,5 \%$ \\
\hline Total & 184 & $100 \%$ \\
\hline
\end{tabular}

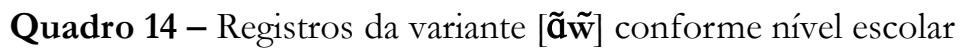
dos informantes 
Como demonstram os quadros 11, 12, 13 e 14, as formas

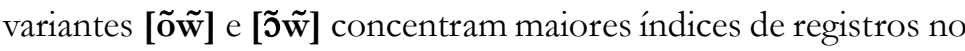
nível de escolaridade fundamental, $88,3 \% 84,6 \%$, respectivamente. Quanto ao nível médio, há registros destas variantes, embora com

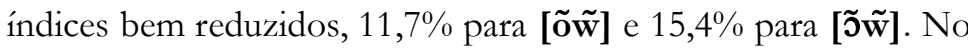
entanto, para o nível de escolaridade superior, não há registros para estas variantes.

Para a variante [ã w̃ ], os registros entre os níveis fundamental e médio apresentam-se equilibrados, $42,2 \%$ e 45,3\%, respectivamente. No nível superior, esta variante é constatada com o percentual de apenas 12,5\% dos registros apresentados.

Diante dos dados apresentados, podemos dizer que os efeitos do processo de aprendizado escolar já se fazem sentir na fala dos informantes entrevistados, pois, dos 278 registros do ditongo nasal ão, 184 são para a forma [ãâw] do português brasileiro, demonstrando, assim, que esta forma já se encontra implementada na fala de todos eles. Tal fato remete aos postulados de Votre (2003), no que diz respeito ao ensino prescritivo, que compreende a aquisição da norma culta por meio da familiarização com novos comportamentos, via repetição das fórmulas propostas, eliminando, assim, formas desprestigiadas e estigmatizadas.

\subsection{Análise dos dados em tempo real}

De acordo com Labov (1996, p. 137), as respostas aos problemas implicados na interpretação do tempo aparente são obtidas ao contar com observações em tempo real. Uma vez apresentados os resultados da análise sincrônica da nova pesquisa, torna-se factível o cotejo com os dados apresentados na obra de Wouk (1981).

Comparando os dados relativos à mudança em tempo real, isto é, os registros de Wouk e os dos informantes desta pesquisa, observamos que:

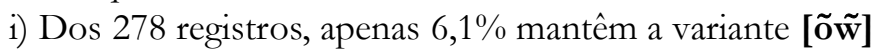
da primeira fase de aquisição apresentada por Wouk na pesquisa realizada na década de 1960; 
ii) Quanto ao vocábulo FEIJÃO, dos 22 registros apresentados, apenas $4,5 \%$ foram produzidos na forma da fase inicial [ $\tilde{\mathbf{o}} \tilde{\mathbf{w}}]$;

iii) Com relação aos vocábulos PINHÃO (Questão 17) e FACÃO (Questão 19), dos 14 registros do primeiro e 11 do segundo, não foi constatada nenhuma produção da forma $[\tilde{\mathbf{o}} \tilde{\mathbf{w}}]$.

De acordo com os dados aqui expostos, podemos dizer que a forma da primeira fase de aquisição do ditongo nasal ão está em via de ser extinta da fala da comunidade ora estudada. Os dados sincrônicos revelaram que os grupos de informantes mais jovens e com maior nível de escolaridade já incorporaram completamente a forma $[\tilde{\mathbf{a}} \tilde{\mathbf{w}}]$ do português brasileiro.

\section{Considerações finais}

Em se tratando do ditongo nasal ão, os resultados da análise

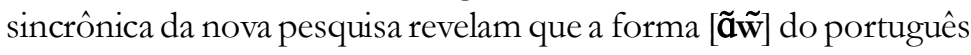
brasileiro encontra-se incorporada na fala de todos os informantes da comunidade ora estudada, porém com índices de uso proporcionalmente diferentes.

Para os três grupos de informantes previamente estabelecidos na metodologia, constatamos que a variável faixa etária é fator determinante quanto ao uso da forma $[\tilde{\mathbf{a}} \tilde{\mathbf{w}}]$ do português brasileiro. Quanto à variante [ $[\tilde{\mathbf{o}} \mathbf{w}]$ previamente descrita por Wouk (1981), revelou-se totalmente eliminada na fala dos informantes da faixa etária 1.

Quanto à variável gênero/sexo, os dados indicam que, embora os homens e as mulheres apresentem índices equilibrados quanto ao uso da variante [ $\tilde{\mathbf{a}} \tilde{\mathbf{w}}], 50,6 \%$ e 49,4\%, respectivamente, as mulheres demonstram ter maior rapidez em absorver a forma variante do ditongo nasal ão prevista pela norma do português brasileiro.

A análise da variável escolaridade revelou que os efeitos do processo de ensino escolar já se fazem sentir na fala desses

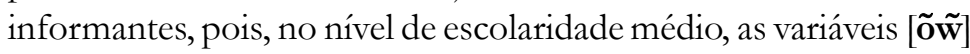




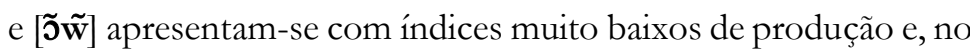
nível escolar superior, não há registros dessas variantes.

Quanto aos aspectos lingüísticos, observamos que se está operando um constante processo de aculturação no sentido de assimilar cada vez mais o português brasileiro. Os dados revelam que as influências da língua ucraniana, em especial no aspecto fonético, estão sendo eliminadas da fala dos mais jovens. Por conseguinte, a manutenção do aprendizado do idioma ucraniano por este grupo de falantes apresenta-se enfraquecida, favorecendo, assim, uma situação de monolinguismo (HEYE; VANDRESEN, 2006).

Constatamos na atual investigação que, decorridos mais de cem anos da chegada dos primeiros imigrantes vindos da parte ocidental da Ucrânia, este grupo étnico conserva nítidos os traços culturais originários, contribuindo, assim, de maneira marcante para a preservação da cultura local.

\section{Referências}

BORTONI-RICARDO, Stella Maris. Nós cheguemu na escola, e agora? Sociolingüística e educação. São Paulo: Parábola, 2005.

COMITÊ NACIONAL DO PROJETO ALiB (Brasil). V Workshop do Projeto Atlas Lingüístico do Brasil (ALiB) WorkALiB. Salvador, UFBA, ago. 2005. (Destinado à discussão da transcrição fonética dos dados do ALiB). [cópia]

Atlas Lingüístico do Brasil: questionários 2001. Londrina: Eduel, 2001.

HEYE, Jürgen Walter Bernd. Sobre o conceito de diglossia. In: GORSKI, E. M.; COELHO, I. L. (Orgs). Sociolingüística e ensino: contribuições para a formação do professor da língua. Florianópolis: Ed. da UFSC, 2006. 
. Línguas em Contato: considerações sobre bilingüismo e bilingualidade. In: RONCARATI, Cláudia; ABRAÇADO, Jussara. (Orgs.). Português Brasileiro: contato lingüístico, heterogeneidade e história. Rio de Janeiro: Sete Letras/FAPERJ, 2003. p. 229-236.

; VANDRESEN, Paulino. Línguas em contato. In: CARDOSO, Suzana Alice Marcelino; MOTA, Jacyra Andrade; SILVA, Rosa Virgínia Matos e. (Orgs.). Quinhentos anos de história lingüística do Brasil. Salvador: Secretaria de Cultura e Turismo do Estado da Bahia, 2006. p. 381-411.

LABOV, William. Principios del cambio lingüístico. Madrid: Gredos, 1996. (Factores internos, v. 1).

. Sociolinguistique. Paris: Les Éditions de Minuit, 1976.

A study of non-Standard English. Washington D.C.: Eric Clearinghouse for Linguistics, 1969.

MOLLICA, Maria Cecilia. Relevância das variáveis não lingüísticas. In: __ _ BRAGA, Maria Luiza. (Orgs.). 2. ed. Introdução à sociolingüística: o tratamento da variação. São Paulo: Contexto, 2004. p. 27-50.

MOREno FERnÁndeZ, Francisco. Princípios de sociolingüística y sociologia del lenguaje. Barcelona: Ariel, 1998.

NARO, Antony Julius. O dinamismo das línguas. In: MOLLICA, Maria Cecília; BRAGA, Maria Luiza. (Org.). 2. ed. Introdução à sociolingüística: o tratamento da variação. São Paulo: Contexto, 2004. p. 43-50.

SILVA NETO, Serafim. Guia para estudos dialetológicos. 2. ed. Belém, Conselho Nacional de Pesquisa/Instituto Nacional de Pesquisas da Amazônia 1957. 
SILVA-CORVALÁN, Carmen. Sociolingüística: teoria y análisis. Madrid: Alhambra, 1989.

TARALLO, Fernando. A pesquisa sociolingüística. São Paulo: Ática, 1985.

; ALKMIN, Tânia. Falares crioulos - línguas em contato. São Paulo: Ática, 1987.

THUN, Harold. A dialetologia no Rio da Prata. In: ZILLES, Ana Maria S. (Org.). Estudos da variação lingüística no Brasil e no Cone Sul. Porto Alegre: UFRGS, 2005.

VANDRESEN, Paulino. Política lingüística e bilingüismo em uma comunidade teuto-brasileira. In: (Org.). Variação, mudança e contato lingüístico no português da Região Sul. Pelotas: EDUCAT, 2006. p. 325-337.

VOTRE, Sebastião Josué. Relevância da variável escolaridade. In: MOLLICA, Maria Cecília; Braga, Maria Luiza (orgs.). Introducão à Sociolingüistica: o tratamento da variação. São Paulo: Contexto, 2004 , p. 51-58.

WOUK, Miguel. Estudo etnográfico-lingüístico da comunidade ucraína de Dorizon. Curitiba: Projeto, 1981. 